\title{
Field Isolates of Tomato spotted wilt virus Overcoming Resistance in Pepper and Their Spread to Other Hosts in Italy
}

Piero Roggero and Vera Masenga, Istituto di Virologia Vegetale, CNR, Strada delle Cacce 73, I-10135 Torino, Italy; Luciana Tavella, Di.Va.P.R.A. Entomologia e Zoologia applicate all'Ambiente "C. Vidano", Università, Via L. da Vinci 44, I-10095 Grugliasco, Torino, Italy

\begin{abstract}
Roggero, P., Masenga, V., and Tavella, L. 2002. Field isolates of Tomato spotted wilt virus overcoming resistance in pepper and their spread to other hosts in Italy. Plant Dis. 86:950-954.

Isolates of Tomato spotted wilt virus (TSWV) severely and systemically infecting commercial pepper cultivars with resistance introgressed from Capsicum chinense PI152225 were found in Albenga (northwestern Italy) in July 2000. Experimentally, these resistance-breaking (RB) isolates overcame the resistance in C. chinense PI152225, but they produced infection in other hosts similarly to non-RB isolates from the same area. The RB isolates were indistinguishable from TSWV by serology and electron microscopy, and they were efficiently transmitted by Frankliniella occidentalis. Such isolates were recovered on the same farm in tomato, pepper, and artichoke 2 and 12 months later, suggesting natural spread from the resistant plants and survival. The RB isolates survived in experimental mixed infections with a non-RB isolate in susceptible pepper and $C$. chinense, but cross-protection in pepper acted against them. Commercial TSWV-resistant pepper but not resistant tomato cultivars from different companies were susceptible to these RB isolates after mechanical inoculation. Similar isolates were not detected among TSWV samples collected from 1993 to 2000 in the area. The management of TSWV and thrips using resistant pepper cultivars is discussed.
\end{abstract}

Tomato spotted wilt virus (TSWV) (Tospovirus, Bunyaviridae) has become one of the most devastating virus diseases of many cultivated plants. Frankliniella occidentalis (Pergande) is the most efficient vector, and since control of this insect is difficult, the damage is always high $(3,7,9,23)$.

Pepper (Capsicum annuum L.) and other Capsicum spp. in both temperate and tropical areas are severely affected $(8,14,16$, 25,27). Heritable resistance to the virus based on a hypersensitive reaction in the $C$. chinense Jacq. accessions PI152225 and PI159236 has been reported (4). A single dominant gene $(T s w)$ is the basis for resistance in both accessions $(12,17,18)$. The gene is not effective against the other tospovirus species: Groundnut ringspot virus (GRSV), Tomato chlorotic spot virus (TCSV) (5), and Impatiens necrotic spot virus (INSV) (20). Only the accession PI152225 is resistant to Watermelon silver mottle virus (10).

Recently, resistant sweet and hot pepper cultivars (all probably derived by crossing with the above two $C$. chinense accessions) have become available from different seed

Corresponding author: P. Roggero

E-mail: p.roggero@ifa.to.cnr.it

Accepted for publication 23 April 2002.

Publication no. D-2002-0709-01R

(C) 2002 The American Phytopathological Society companies and are grown in Italy and elsewhere. In Albenga (Liguria, northwestern Italy), sweet peppers are widely grown mainly in glasshouses from April to September or later. In this area, the climate is mild, with minimum winter temperatures about $5^{\circ} \mathrm{C}$, and many vegetable and ornamental crops susceptible to TSWV are raised both in the open and under cover all year. Severe damage in pepper due to TSWV has been noted since 1992 (25,27). Resistant cultivars from Petoseed were tested in preliminary trials in 1998 , and in August, TSWV isolates able to overcome their resistance were found in only two plants grown among other susceptible plants in a glasshouse in the area (21). The two isolates were efficiently transmitted by F. occidentalis, and their host ranges and serological properties were those of other TSWV isolates producing a hypersensitive reaction in these plants and the parental line C. chinense PI152225.

Since 1999, resistant cultivars from different companies have been widely grown in the area. In one glasshouse with about 3,000 plants of the resistant cvs. Explorer and Sunny (from Petoseed), the end of July 2000 saw all plants with severe TSWV-like symptoms on fruits and leaves which tested positive for TSWV by enzymelinked immunosorbent assay (ELISA). We report the biological and serological characterization of isolates from those plants. We have further evaluated these resistancebreaking (RB) isolates by inoculation to $C$. chinense PI152225 in other crops on the farm the same year and in 2001 and for their presence among TSWV isolates collected before introduction of resistant cultivars in the area. Commercial pepper and tomato cultivars resistant to TSWV have also been tested for their susceptibility to these RB isolates.

\section{MATERIALS AND METHODS}

Field surveys. Plants were sampled from a 1-ha farm, located in Albenga (northwestern Italy, Liguria), which was close to other farms growing crops susceptible to TSWV (Fig. 1). Production in the open and in glasshouses is mainly devoted to pepper, tomato, and artichoke. Pepper is grown from spring under glass; tomato is grown under glass in winter and both in the open and under glass in spring-summer. Artichoke is grown only in the open. Thrips are controlled occasionally by chemical treatments. TSWV-infected plants are sometimes removed from the growing area and allowed to dry out in the open.

Pepper cvs. Explorer and Sunny (Petoseed) planted in April under glass showed severe TSWV-like symptoms on leaves and fruits at the end of July 2000. They were tested for TSWV by ELISA, observed by thin-sectioning and electron microscopy, and two isolates (P223 and P224 from cvs. Explorer and Sunny, respectively) were further investigated. In the middle of September, a second survey was done, and samples from pepper, tomato, and artichoke showing TSWV-like symptoms were collected. Pepper and tomato showing TSWV-like symptoms were sampled again at the end of July 2001, and at the same time from a farm about $5 \mathrm{~km}$ away. Leaf samples infected with TSWV from different hosts collected in the same area from 1993 to 2000 were kept stored under liquid nitrogen and inoculated (see below) to Nicotiana benthamiana Domin.

ELISA. Double antibody sandwich (DAS) and triple antibody sandwich (TAS) ELISA with rabbit polyclonal antibodies against TSWV or INSV nucleocapsid, or TSWV glycoproteins, and monoclonal antibodies (MAbs) against TSWV or INSV nucleocapsid or the glycoproteins have been described $(1,2,22)$. DAS-ELISA with polyclonal antibodies against TSWV nucleocapsid was used to detect TSWV, GRSV, and TCSV. The MAb APO against glycoprotein was used in TAS-ELISA to 
evaluate the presence of glycoproteins as a general assay for tospoviruses. To discriminate TSWV from GRSV and TCSV, the MAb 4F2, which reacts strongly with TSWV and has a faint reaction with GRSV but no reaction with TCSV, has been used. INSV was detected using the MAb 5E4. TSWV isolate P105 (isolated from pepper in 1995 in the same area), GRSV isolate SA05, TCSV isolate BR03, and INSV isolate Glox1 were used as positive controls (1). All steps were performed with a volume of $100 \mu \mathrm{l} /$ well, and the samples were replicated in two wells. The plates were of the high protein binding type (Greiner, Kremsmünster, Austria) and were coated with polyclonal antibodies at 1 $\mu \mathrm{g} / \mathrm{ml}$. Samples were homogenized with phosphate buffered saline (PBS) plus $0.05 \%$ Tween 20 and $2 \%$ polyvinylpyrrolidone (molecular weight about 30,000) and used diluted 1:100 (wt/vol) together with healthy controls. Polyclonal antibodies conjugated with alkaline phosphatase were diluted 1:500 and MAbs at $1 \mu \mathrm{g} / \mathrm{ml}$. MAbs were detected with an anti-mouse IgGalkaline phosphatase conjugate (Sigma Co., St. Louis, MO). Substrate for alkaline phosphatase was $p$-nitrophenyl phosphate (Fluka Chemie, Buchs, Switzerland) at 1 $\mathrm{mg} / \mathrm{ml}$ in $\mathrm{pH} 9.8$ diethanolamine buffer. Absorbance was read by using the automatic reader Mod. 3550 (Bio-Rad Laboratories, Hercules, CA), with the dual wavelength mode at $405 \mathrm{~nm}$ and $490 \mathrm{~nm}$, after 2 $\mathrm{h}$ of reaction at room temperature. Samples having absorbance three or more times that of the healthy controls were considered positive.

Mechanical inoculation. Plants were grown in sterilized soil in an insect-proof glasshouse, maintained at 20 to $30^{\circ} \mathrm{C}$, under natural light and sometimes with light supplemented by sodium lamps. Leaf and fruit samples were homogenized in $0.05 \mathrm{M}$ phosphate buffer $\mathrm{pH} 7$ (1:10 wt/vol) containing $1 \mathrm{mM}$ Na-EDTA, $5 \mathrm{mM} \mathrm{Na}$ DIECA, $5 \mathrm{mM}$ Na-thioglycolate, and 50 $\mathrm{mg} / \mathrm{ml}$ activated charcoal (Farmitalia Carlo Erba, Milano, Italy); the sap was immediately inoculated by leaf rubbing to Carborundum-dusted leaves. For all experiments, plants having four to six leaves were inoculated. Plants used were: $C$. annuum cv. Quadrato d'Asti (highly susceptible to TSWV and other tospoviruses), $C$. chinense PI152225 and PI159236 (reacting hypersensitively to TSWV), Chenopodium quinoa Willd., Datura stramonium L., Lycopersicon esculentum Mill. cv. Marmande, $N$. benthamiana, $N$. clevelandii A. Gray, N. tabacum L. cv. White Burley type, and Petunia $\times$ hybrida (Hooker) Vilmorin.

Testing commercial pepper and tomato cultivars resistant to TSWV with the RB isolates. Seeds of commercial pepper and tomato cultivars resistant to TSWV were obtained from De Ruiter Sementi, Novartis, and Petoseed. The follow- ing cultivars were tested: peppers DRP 5170 and DRH 7033, tomatoes Valiente, Rovente, and Hermes from De Ruiter Sementi; peppers Antolin, RL 588, and 589 from Novartis; peppers Explorer and Sunny and tomato PS881 from Petoseed. Three TSWV isolates were used: P105 (a non-RB isolate) and P223 and Cy35 (RB isolates from pepper and artichoke, respectively). Plants were observed for symptom development for up to 3 weeks, and infections were confirmed by ELISA or by back-inoculation.

Possible antagonism in susceptible pepper and $C$. chinense PI152225 among the RB isolates and a non-RB isolate. Isolates P223 and Cy35 (RB isolates) were each inoculated in combination with P105 (non-RB) from singly infected $N$. benthamiana to pepper cv. Quadrato d'Asti and to C. chinense PI152225 using three different procedures. Presence of the RB isolates in the infected plants was inferred in $C$. chinense directly by the presence of systemic symptoms, whereas in pepper it was confirmed by back-inoculation to $C$. chinense PI152225 and the development of systemic symptoms. In the first procedure, sap containing the isolates was mixed and inoculated at the same time. In the second procedure, the viruses were inoculated at the same time into different leaves. In the third procedure, pepper was inoculated with P105, and 1 week later, two systemically invaded leaves were inoculated with P223 or Cy35. One week later, the challenged inoculated pepper leaves were back-inoculated to $C$. chinense.

Transmission by $F$. occidentalis. Isolates P223 and P224 were tested. To obtain

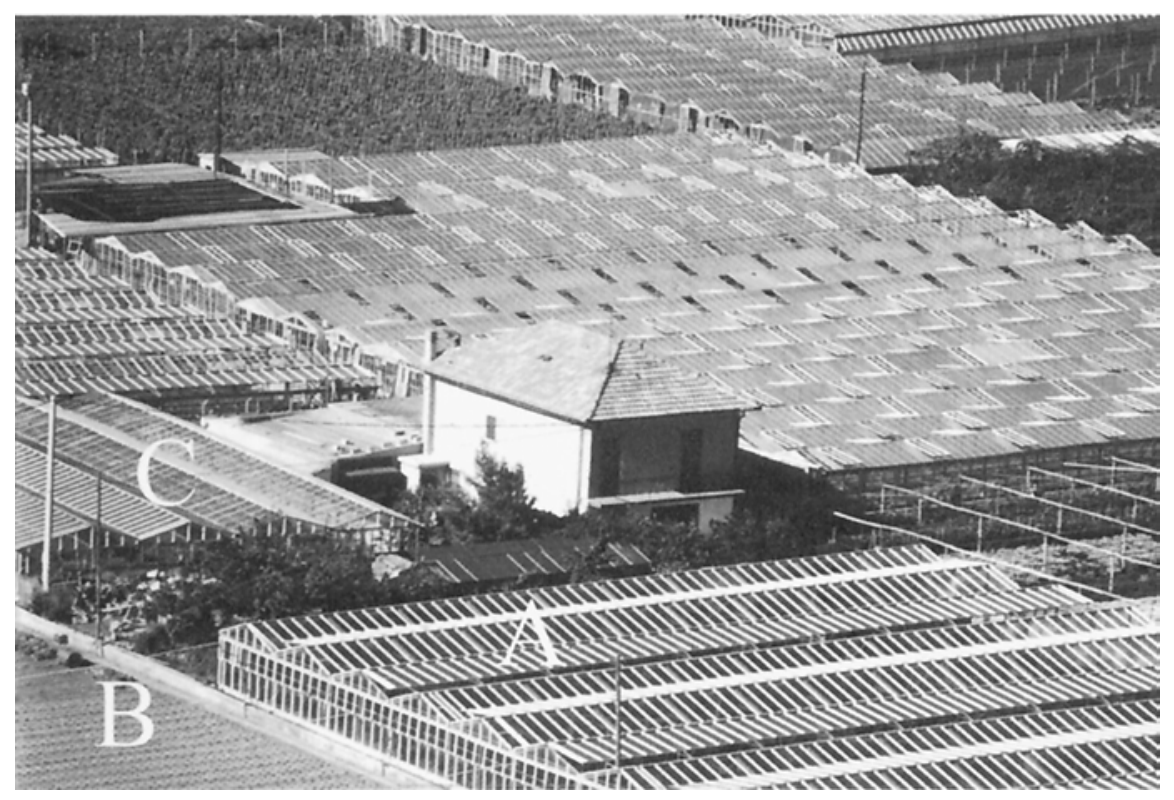

Fig. 1. Overview of the farm where pepper plants resistant to Tomato spotted wilt virus were cultivated in 2000. Pepper plants found infected by the resistance-breaking strains in July were grown in the glasshouse (A). In the field (B) close to the glasshouse, tomato and artichoke were grown, and infected pepper plants from (A) were laid out to dry in August. Other infected tomato and pepper plants were found in September in glasshouse (C) on the left side of the house.
TSWV-free colonies of $F$. occidentalis, specimens collected in northwestern Italy (26) were reared on French bean pods and pollen, and the transmission trials were carried out following Wijkamp and Peters (28). All trials were done at $25 \pm 1{ }^{\circ} \mathrm{C}, 60 \%$ $\mathrm{RH}$, with a 16 -h photoperiod and a light intensity of about $100 \mu \mathrm{mol} \cdot \mathrm{m}^{-2} \cdot \mathrm{s}^{-1}$ photosynthetically active radiation (Philips TLD 95 lamps).

To allow oviposition, adults were isolated in plastic petri dishes (diameter 90 $\mathrm{mm}$ ) on cucumber leaves. After 4 days, the adults were removed and the leaves were observed every $2 \mathrm{~h}$ to collect newly hatched larvae, which were put in Plexiglas cages (24) on D. stramonium leaves showing systemic symptoms. After $48 \mathrm{~h}$, the larvae were transferred to other cages on healthy cucumber leaves to complete their development. A day after emergence, the adults were put singly in plastic tubes $(1.5 \mathrm{ml})$ with a leaf disk (diameter $10 \mathrm{~mm}$ ) of pepper cv. Quadrato d'Asti. This was replaced twice at intervals of 72 $h$. The disks were then incubated in 24well tissue culture plates for $72 \mathrm{~h}$ while floating on water under light at a temperature of about $25^{\circ} \mathrm{C}$. The presence of TSWV in the disks was monitored by ELISA.

Electron microscopy. Glutaraldehydeosmium fixation and epoxy embedding was applied to naturally infected leaves or fruits of Explorer and Sunny to study the cytopathology and in situ particle morphology. TSWV morphology was also studied by uranyl acetate negative staining of crude sap from the same plants (15). Negative staining was also used to check for the presence of other viruses. 


\section{RESULTS}

Field survey. In July 2000, severe TSWV-like symptoms and thrips damage were observed on fruits and leaves of most plants of Explorer and Sunny. On old leaves, symptoms consisted mainly of chlorotic necrotic spots, whereas on young leaves, symptoms were chlorosis and necrosis and wilting of the shoots. On fruits, necrotic rings and malformations were observed. Leaf and fruit samples randomly collected tested positive by TAS-ELISA for TSWV with the specific MAb 4F2 and for glycoprotein with the MAb APO but not with the MAb 5E4 specific for INSV. By electron microscopy after negative staining, only typical clusters of TSWVlike particles were observed. These plants were removed by the middle of August.

In the second survey in September, TSWV-like symptoms on leaves and fruits were observed on different tomato cultivars grown in another glasshouse close to the pepper glasshouse. TSWV-like symptoms were also seen on different pepper cultivars not resistant to TSWV. In the open, some artichoke plants showed necrotic symptoms on young leaves. A total of 40 samples from tomato, pepper, and artichoke were collected. All samples tested positive for TSWV with MAb 4F2, for glycoproteins with MAb APO, and not for INSV with MAb 5E4. Infected tomato and pepper plants were removed progressively. The only overwintering plants in the open were artichokes, removed in April 2001, so there was some overlap with tomato under glass.

During the third survey in July 2001, severe TSWV-like symptoms were observed in about $50 \%$ of 200 tomato plants of different cultivars grown in the open and in some pepper plants under glass. Twentytwo samples were collected, and all tested positive in ELISA for TSWV. At the same time, five samples were collected in another farm about $5 \mathrm{~km}$ away, which also tested positive for TSWV as above. The serological analysis of the TSWV isolates is reported in Table 1.

Mechanical inoculation. Samples from the pepper cvs. Explorer (P223) and Sunny

Table 1. Characterization of Tomato spotted wilt virus (TSWV) isolates by double antibody sandwich (DAS) and triple antibody sandwich (TAS) enzyme-linked immunosorbent assay (ELISA) protocols with different specificity for the other tospoviruses, Groundnut ringspot virus (GRSV), Impatiens necrotic spot virus (INSV), and Tomato chlorotic spot virus (TCSV)

\begin{tabular}{llcccc}
\hline Virus origin & Isolate & $\begin{array}{c}\text { DAS } \\
\text { TSWV }^{\mathbf{b}}\end{array}$ & $\begin{array}{c}\text { TAS } \\
\text { TSWV }^{\mathbf{c}}\end{array}$ & $\begin{array}{c}\text { TAS } \\
\text { INSV }^{\mathbf{d}}\end{array}$ & $\begin{array}{c}\text { TAS } \\
\text { tospovirus }^{\mathbf{e}}\end{array}$ \\
\hline Survey July 2000 & P223 & 0.79 & 0.72 & 0.05 & 0.39 \\
& $\mathrm{P} 224^{\mathrm{f}}$ & 0.78 & 0.75 & 0.04 & 0.23 \\
& Cy35 & 0.80 & 0.71 & 0.04 & 0.26 \\
& $\mathrm{P}^{\mathrm{f}}$ & 0.72 & 0.42 & 0.06 & 0.13 \\
& $\mathrm{~T}^{\mathrm{f}}$ & 1.17 & 0.84 & 0.05 & 0.57 \\
& $\mathrm{~T}^{\mathrm{f}}$ & 0.98 & 0.44 & 0.05 & 0.74 \\
& $\mathrm{Cy}$ & 1.09 & 0.85 & 0.03 & 0.41 \\
& Cy & 1.07 & 0.83 & 0.05 & 0.50 \\
& $\mathrm{P}$ & 0.90 & 0.85 & 0.04 & 0.50 \\
& $\mathrm{P}$ & 1.03 & 0.78 & 0.04 & 0.27 \\
& $\mathrm{P}$ & 1.19 & 0.74 & 0.06 & 0.67 \\
& $\mathrm{~T}$ & 0.86 & 0.65 & 0.04 & 0.05 \\
& $\mathrm{~T}$ & 1.02 & 0.48 & 0.03 & 0.95 \\
& $\mathrm{~T}$ & 0.70 & 0.24 & 0.03 & 0.40 \\
& $\mathrm{~T}^{\mathrm{f}}$ & 1.01 & 0.76 & 0.04 & 0.45 \\
& $\mathrm{~T}^{\mathrm{f}}$ & 0.77 & 0.76 & 0.06 & 0.37 \\
& $\mathrm{~T}$ & 1.06 & 0.60 & 0.06 & 0.12 \\
& $\mathrm{~T}$ & 0.99 & 0.57 & 0.05 & 0.88 \\
& $\mathrm{P}$ & 1.19 & 0.85 & 0.05 & 0.47 \\
& $\mathrm{P}$ & 0.87 & 0.78 & 0.06 & 0.37 \\
& $\mathrm{P}$ & 0.83 & 0.56 & 0.04 & 0.17 \\
& $\mathrm{P}$ & 1.10 & 0.62 & 0.05 & 0.53 \\
& $\mathrm{P}^{\mathrm{g}}$ & 1.07 & 0.73 & 0.05 & 0.39 \\
& $\mathrm{P}^{\mathrm{g}}$ & 1.22 & 0.81 & 0.04 & 0.51 \\
& $\mathrm{~T}^{\mathrm{g}}$ & 0.81 & 0.67 & 0.05 & 0.19 \\
& Healthy & 0.03 & 0.04 & 0.04 & 0.05 \\
& TSWV P105 & 0.46 & 0.78 & 0.06 & 0.51 \\
& TCSV BR-03 & 0.42 & 0.07 & 0.04 & 0.45 \\
& GRSV SA-05 & 0.38 & 0.12 & 0.06 & 0.56 \\
& $\mathrm{INSV}$ Glox1 & 0.03 & 0.04 & 1.23 & 0.60 \\
\hline
\end{tabular}

${ }^{\mathrm{a}}$ Isolates are labeled $\mathrm{P}$ for pepper, $\mathrm{T}$ for tomato, and $\mathrm{Cy}$ for artichoke. All samples were from experimentally infected Nicotiana benthamiana and were diluted 1:100 (wt/vol).

b Polyclonal antiserum against TSWV nucleocapsid.

${ }^{c}$ Polyclonal antiserum and monoclonal antibody against TSWV nucleocapsid.

d Polyclonal antiserum and monoclonal antibody against INSV nucleocapsid.

${ }^{\text {e }}$ Polyclonal antisera against TSWV nucleocapsid and glycoprotein and monoclonal antibody against TSWV glycoprotein.

${ }^{\mathrm{f}}$ Isolates typed as TSWV resistance-breaking strains based on the systemic invasion of Capsicum chinense PI152225.

${ }^{\mathrm{g}}$ Isolates coming from another farm without history of pepper-resistant plants.

(P224) were inoculated to the plants listed above. Typical TSWV symptoms were observed with all Nicotiana species, and tomato and pepper reacted with severe systemic infection; on $C$. quinoa and petunia only local lesions were observed. With C. chinense PI152225 and PI159236, local lesions, either chlorotic or necrotic, appeared 2 to 3 days after inoculation, followed by severe necrotic symptoms appearing irregularly 1 week later.

From the second survey done in September, of the 40 samples inoculated, four isolates (one from pepper, two from tomato, and one from artichoke [Cy35]) were $\mathrm{RB}$ isolates based on systemic infection of C. chinense PI152225; all other isolates produced only local lesions on $C$. chinense PI152225 not followed by systemic invasion. For all other hosts, infection was typical of TSWV, with symptoms of different intensity.

From the survey done in July 2001, 14 samples came from tomato and 8 from pepper. Only two samples from tomato and none from pepper were typed as RB isolates. Some pepper assay plants were also infected by Cucumber mosaic virus. All other samples gave variable symptoms on the different hosts but only a local infection in $C$. chinense PI152225. The samples from the other farm, without a history of resistant pepper, were typed as normal TSWV isolates.

The presence of RB isolates was confirmed by comparison with 13 isolates collected in the same area from 1993 to 2000. TAS-ELISA with MAb 4F2 typed all these isolates as TSWV (data not shown). The originally infected plants were tomato, pepper, cineraria, blue daisy, Euphorbia sp., artichoke, daisy, and Aster sp. None of these isolates infected systemically $C$. chinense PI152225.

Testing commercial pepper and tomato cultivars resistant to TSWV with the RB isolates. All resistant pepper cultivars developed severe systemic necrotic symptoms of different intensity with the RB isolates P223 and Cy35 and only local lesions with the non-RB isolate P105. With all resistant tomato cultivars, no symptoms developed; however, virus isolates Cy35 and P105 but not P223 were detected by ELISA in the inoculated leaves of all the cultivars.

Possible antagonism in susceptible pepper and $C$. chinense PI152225 among the RB isolates and a non-RB isolate. Results were the same with both RB isolates P223 and Cy35. In the first and second procedures, systemic symptoms developed in C. chinense, and the RB isolates were recovered from systemically infected pepper leaves 10 days after inoculation. In the third procedure, the RB strains were not detected in the challenged inoculated pepper leaves back-inoculated to $C$. chinense, which developed only a local infection. 
Transmission by $\boldsymbol{F}$. occidentalis. Isolate P223 was transmitted from $D$. stramonium to pepper with an efficiency of $88 \%$ (43 adult thrips individually tested). Isolate P224 was transmitted with an efficiency of 74\% (42 adult thrips tested). Of 45 larvae acquiring the virus directly from the naturally infected leaves of cv. Explorer, only nine survived until adulthood; eight of these transmitted the virus to pepper leaf disks.

Electron microscopy. In negatively stained crude sap preparations from the original leaf and fruit tissues of cvs. Explorer and Sunny, TSWV-like particles with typical morphology were observed in clusters or as scattered particles. The appearance of TSWV in thin sections of leaves and fruits was similar, with typical structures always present (data not shown).

\section{DISCUSSION}

Serological analysis with monoclonal antibodies against the TSWV nucleocapsid showed that all $\mathrm{RB}$ and non-RB isolates were TSWV and not GRSV or TCSV. This confirms that in Albenga the only Tospovirus species present, besides INSV, is TSWV $(22,27)$. Thus, systemic infection of resistant pepper cannot be ascribed to the presence of GRSV or TCSV, both of which are able to infect these plants systemically (5).

The RB strains appear to overcome the $T s w$ gene in Capsicum, and they are not able to overcome resistance in different tomato cultivars carrying the $S w-5$ gene. It has been shown that the two genes are different (12). In other aspects, the RB isolates behave like other TSWV isolates systemically infecting some hosts but still giving only local lesions in petunia and $C$. quinoa (7).

The presence of these RB isolates appears related to the presence of resistant plants, since similar isolates have not been found before such crops were grown, or on other farms where they were absent. TSWV exists as a complex population (11), and probably the selective pressure of resistant plants led to the emergence of these isolates. In fact, RB isolates have also been found after experimental inoculation (17) or in the field (21).

Selection of RB isolates overcoming the resistance is a possible phenomenon when resistant plants are cultivated, especially with a truly vertical resistant gene like $T s w$ in pepper $(6,13)$. However, the ability to overcome a resistance gene sometimes results in selection of virus isolates with loss of other properties and lower pathogenic fitness (6). This was not so in our experiments, as both in the field and in experimental trials, these RB isolates behaved like normal TSWV. Their experimental host range, the virus particles, and the ultrastructural alterations observed were identical to those of normal isolates, and they were transmitted with high effi- ciency by $F$. occidentalis. Furthermore, they survived in mixed infections with a normal isolate in pepper when co-infection was simultaneous. However, the RB isolates were not able to infect a plant previously infected by a non-RB isolate, suggesting that cross-protection acted against them, confirming their close relatedness to the wild-type isolate (P105). The RB isolates were found in other plant hosts up to 1 year later, suggesting spread from the infected resistant pepper.

TSWV has the widest host range among plants viruses (7), and the generation of $\mathrm{RB}$ isolates confirms the plasticity of the virus (3). The divided genome of the virus potentially allows recombination and reassortment as well as simple mutation, facilitating evolution to a new pathotype (19). Resistance breaking in pepper in one artificial isolate of the virus has been mapped to the smallest RNA segment (12). Strains are able to overcome the resistance in tomato carrying the $S w-5$ gene or transgenic plants expressing the nucleoprotein, and changes in these isolates are associated mutations, always in the M RNA segment (11). The isolates we have typed as RB may provide material for further analysis at the molecular level to identify the change in the genome responsible for breaking resistance. These isolates should also be used to search for new resistant sources among Capsicum sp.

All the commercial resistant pepper cultivars from different companies we have tested are susceptible to these RB isolates, indicating that probably the resistant gene introgressed has a similar origin, and the genetic background has little or no influence on the expression of the resistance gene. This suggests caution in the use of these cultivars, although they presently represent the only realistic possibility of growing pepper in areas heavily infected by TSWV. In 2001, various resistant cultivars were widely and successfully grown in the area, and we have found only one plant with TSWV-like symptoms again infected with an RB isolate. The farm we have investigated is probably atypical because of a persistent and heavy infestation of $F$. occidentalis, and no precautions were taken to eliminate the infected plants. Thus, the use of resistant plants must be combined with careful control of the thrips and the early removal of infected plants to reduce the spread of the virus to other crops.

\section{ACKNOWLEDGMENTS}

Paper No. 35. Research done in the framework of the National Research Programme on Vegetable Crops of the Italian Ministry of Agricultural Policies. We thank seed companies for providing seeds of the different varieties, G. Bozzano of Cooperativa L'Ortofrutticola, Albenga, for help on the field survey, C. Perrone for technical assistance, and R. G. Milne for revision of the text.

\section{LITERATURE CITED}

1. Adam, G., Peters, D., and Goldbach, R. W. 1997. Serological comparison of tospovirus isolates using polyclonal and monoclonal antibodies. Acta Hortic. 431:135-158.

2. Adam, G., Roggero, P., Malavasi, F., Milne, R. G., and Papa, G. 1995. Approach to a general tospovirus assay using antibodies to purified tomato spotted wilt tospovirus $G$ proteins. Bull. OEPP 25:247-257.

3. Adkins, S. 2000. Tomato spotted wilt virus Positive steps towards negative success. Mol. Plant Pathol. 1:151-157.

4. Black, L. L., Hobbs, H. A., and Gatti, J. M., Jr. 1991. Tomato spotted wilt virus resistance in Capsicum chinense PI 152225 and 159236. Plant Dis. 75:863.

5. Boiteux, L. S., and De Avila, A. C. 1994 Inheritance of a resistance specific to tomato spotted wilt tospovirus in Capsicum chinense 'PI 159236'. Euphytica 75:139-142.

6. Fraser, R. S. S. 1990. The genetics of resistance to plant viruses. Annu. Rev. Phytopathol. 28:179-200.

7. German, T. L., Ullman, D. E., and Moyer, J. W. 1992. Tospoviruses: Diagnosis, molecular biology, phylogeny, and vector relationships. Annu. Rev. Phytophathol. 30:315-348.

8. Gitaitis, R. D., Dowler, C. C., and Chalfant, R. B. 1998. Epidemiology of tomato spotted wilt in pepper and tomato in southern Georgia. Plant Dis. 82:752-756.

9. Goldbach, R. W., and Peters, D. 1994. Possible causes of the emergence of Tospovirus diseases. Seminars Virol. 5:113-120.

10. Green, S. K., Hwang, J. T., and Chou, J. C. 1996. Evaluation of selected Lycopersicon and Capsicum germ plasm for watermelon silver mottle tospovirus resistance. Plant Dis. 80:824.

11. Hoffmann, K., Qiu, W. P., and Moyer, J. W. 2001. Overcoming host- and pathogenmediated resistance in tomato and tobacco maps to the M RNA of Tomato spotted wilt virus. Mol. Plant-Microbe Interact. 14:242249.

12. Jahn, M., Paran, I., Hoffmann, K., Radwanski, E. R., Livingstone, K. D., Grube, R. C., Aftergoot, E., Lapidot, M., and Moyer, J. W. 2000. Genetic mapping of the Tsw locus for resistance to the Tospovirus Tomato spotted wilt virus in Capsicum spp. and its relationship to the $S w-5$ gene for resistance to the same pathogen in tomato. Mol. Plant-Microbe Interact. 13:673-682.

13. Khetarpal, R. K., Maisonneuve, B., Maury, Y., Chalhoub, B., Dinant, S., Lecoq, H., and Varma, A. 1998. Breeding for resistance to plant viruses. Pages 14-32 in: Plant Virus Disease Control. A. Hadidi, R. K. Khetarpal, and H. Koganezawa, eds. American Phytopathological Society, St Paul, MN.

14. Lima, M. F., de Avila, A. C., de Resende, R. and Nagata, T. 2000. Survey and identification of Tospovirus species in tomato and pepper fields in the San Francisco Valley and Federal District. Summa-Phytopathol. 26:205210.

15. Milne, R. G. 1970. An electron microscope study of tomato spotted wilt virus in sections of infected cells and in negative stain preparations. J. Gen. Virol. 6:267-276.

16. Momol, M. T., Pappu, H. R., Dankers, W., Rich, J. R., and Olson, S. M. 2000. First report of Tomato spotted wilt virus in habanero and tabasco peppers in Florida. Plant Dis. 84:1154.

17. Moury, B., Palloix, A., Selassie-Gebre, K., and Marchoux, G. 1997. Hypersensitive resistance to tomato spotted wilt virus in three Capsicum chinense accessions is controlled by a single gene and is overcome by virulent strains. Euphytica 94:45-52.

18. Moury, B., Pflieger, S., Blattes, A., Lefebvre, V., and Palloix, A. 2000. A CAPS marker to assist selection of tomato spotted wilt virus 
(TSWV) resistance in pepper. Genome 43:137142.

19. Qiu, W. P., Geske, S. M., Hickey, C. M., and Moyer, J. W. 1998. Tomato spotted wilt tospovirus genome reassortment and genome segment-specific adaptation. Virology 244:186194.

20. Roggero, P., Dellavalle, G., Ciuffo, M., and Pennazio, S. 1999. Effects of temperature on infection in Capsicum sp. and Nicotiana benthamiana by impatiens necrotic spot tospovirus. Eur. J. Plant Pathol. 105:509-512.

21. Roggero, P., Melani, V., Ciuffo, M., Tavella, L., Tedeschi, R., and Stravato, V. M. 1999. Two field isolates of tomato spotted wilt tospovirus overcome the hypersensitive response of a pepper (Capsicum annuum) hybrid with resistance introgressed from $C$. chinense PI152225. Plant Dis. 83:965.

22. Roggero, P., Ogliara, P., Dellavalle, G., Lisa, V., Malavasi, F., and Adam, G. 1997. A general tospovirus assay using monoclonal antibodies against tomato spotted wilt virus glycoproteins. Acta Hortic. 431:167-175.

23. Rosello, S., Diez, M. J., and Nuez, F. 1996 Viral diseases causing the greatest economic losses to the tomato crop. I. The tomato spotted wilt virus - a review. Sci. Hortic. 67:117150 .

24. Tashiro, H. 1967. Selfwatering acrylic cages for confining insects and mites on detached leaves. J. Econ. Entomol. 60:354-356.

25. Tavella, L., Alma, A., Conti, A., Arzone, A., Roggero, P., Ramasso, E., Dellavalle, G., and Lisa, V. 1997. Tripidi e TSWV nelle serre di peperone in Liguria. Colture Protette 26:79-
83

26. Tavella, L., Roggero, P., Ogliara, S., Ciuffo, M., Vaira., A. M., and Arzone, A. 1998 Transmission of tomato spotted wilt tospovirus by Frankliniella occidentalis from Liguria (north-western Italy). Abstr. Int. Sympos. Tospoviruses Thrips Floral Veg. Crops, 4th Wageningen, Netherlands

27. Vaira, A. M., Roggero, P., Luisoni, E., Masenga, V., Milne, R. G., and Lisa, V. 1993. Characterization of two Tospoviruses in Italy: Tomato spotted wilt and impatiens necrotic spot. Plant Pathol. 42:530-542.

28. Wijkamp, I., and Peters, D. 1993. Determination of the median latent period of two tospoviruses in Frankliniella occidentalis, using a novel leaf disk assay. Phytopathology 83:986-991. 